\title{
Multitud y teoría ascendente del poder: reflexiones acerca de la posibilidad de una democracia radical
}

\author{
The Multitude and the Ascending Theory of Power: \\ Reflections on the Possibility of a Radical Democracy
}

Multidão e teoria ascendente do poder: reflexões sobre a
possibilidade de uma democracia radical

Dra. Pamela Soto García'

Recibido: 25/08/2016 - Aceptado: 23/10/2016

\begin{abstract}
Resumen
La recuperación de la "teoría ascendente del poder", emergida en la Baja Edad Media, a partir de los aportes teóricos de autores tales como Bartolo Sassoferrato y Marsilio de Padua, proporciona elementos para el análisis de fenómenos políticos contemporáneos, en especial respecto a las consideraciones que se presentan a través del término "multitud", en cuanto este término permite comprender y cuestionar fenómenos y teorías políticas, que transitan desde el posicionamiento de la reflexión acerca del conflicto a la implementación de una democracia radical.
\end{abstract}

Palabras Clave: multitud - democracia - conflicto - teoría ascendente del poder.

1 Pamela Soto García, chilena, Doctora y Lincencida en Filosofía por la Pontificia Universidad Católica de Valparaíso, Chile. Desde el año 2012 se desempeña como Profesora de Filosofía Política en el Instituto de Filosofía de la Pontificia Universidad Católica de Valparaíso, pamela.soto@pucv.cl. Este texto es parte del proyecto de investigación (37.0/2014) "La comprensión del sujeto político y sus implicancias para la democracia, a partir de la noción de conflicto en el pensamiento de María Zambrano y Roberto Esposito", financiado por el Fondo Concursable de Iniciación a la Investigación otorgado por la Vicerrectoría de Investigación y Estudios Avanzados de la Pontificia Universidad Católica de Valparaíso. 


\begin{abstract}
The recovery of the "ascending theory of power", emerged in the Late Middle Age from the theoretical contributions by authors such as Bartolo Sassoferrato and Marsilio de Padua, provides elements for the analysis of contemporary political phenomena, especially regarding to the considerations presented through the term "multitude", since this term allows to understand and question political phenomena and theories, that move from the positioning of reflection on conflicts to the implementation of a radical democracy.
\end{abstract}

Keywords: Multitude - democracy - conflict - ascending theory of power.

\title{
Resumo:
}

A recuperação da "teoria ascendente do poder" que surge no final da Idade Média, a partir das contribuições teóricas de autores como Bartolo Sassoferrato e Marsilio de Padua, proporcionam elementos para a análise dos fenómenos políticos contemporâneos, especialmente no que diz respeito às considerações apresentadas pelo termo "multidão", enquanto este termo nos permite compreender e questionar os fenômenos e teorias políticas, que transitam a partir da posição de reflexão sobre o conflito com a implementação de uma democracia radical.

Palavras-chave: multidão - democracia - conflito - teoria ascendente do poder.

Las sociedades democráticas se han identificado, a partir de la Modernidad, desde la articulación de un sujeto político que se considera como un individuo que instituye su acción desde el supuesto de la búsqueda del orden social como tendencia propia de sus actos. Sin embargo, las condiciones de la sociedad actual requieren la comprensión de una subjetividad política distinta, en tanto que ésta permita que el conflicto sea considerado como aquello que organiza la acción del campo de lo político. En efecto, la fragmentación de lo político que ocasiona la figura del individuo como representación de una subjetividad particular, desde la cual se constituye la organización del campo de lo político, debe desplazarse hacia la comprensión de una subjetividad colectiva que permita una nueva comprensión para dicho campo.

El giro en la comprensión del registro de la subjetividad desde el individuo al colectivo responde a la necesidad de pensar el fenómeno político desde las actuales condiciones de su ejercicio, en las que los 
diversos alzamientos populares que se han organizado durante los últimos años, dan testimonio de una fractura en el vínculo directo que, a partir de la Modernidad, se estableció entre democracia, colectivo y representación (Negri 2011).

Estos levantamientos populares, por consiguiente, ameritan ser pensados filosóficamente, y desde esta perspectiva ahondar en el cuestionamiento que propician acerca de la comprensión de un tipo de subjetividad política que se organiza desde una concepción afirmativa del conflicto, y que aborda la subjetivación humana desde una dimensión colectiva.

Este vínculo entre conflicto y subjetividad, no sólo responde a consideraciones filosóficas actuales, sino que encuentra aportes relevantes en la "teoría ascendente del poder" del mundo medieval. El presente artículo pretende, por consiguiente, recuperar críticamente la "teoría ascendente del poder", emergida en la Baja Edad Media, a fin de entregar elementos teóricos para el análisis de fenómenos políticos contemporáneo que apuntan al ejercicio de una democracia radical, entendida esta última como expresión de un cuerpo colectivo heterogéneo que se expresa políticamente desde su diferencia, estableciendo con ello otros referentes para la comprensión de la relación entre conflicto y subjetividad en el campo de lo político.

El desarrollo de este análisis se articula a partir de tres momentos; en el primero de ellos se revisarán los antecedentes medievales para la comprensión de la "teoría ascendente del poder", a partir del desglose de tres "formas políticas", en las que se representan los diversos modos como se instituye el poder en un territorio. Este apartado permitirá establecer a la ciudad como aquella "forma política" que permite analizar la inmanencia del poder desde la multitudo, entendida esta última como expresión de una subjetivación colectiva.

En el segundo apartado se evidenciará la emergencia de la "teoría ascendente del poder" en la Baja Edad Media, a partir de la exposición del ejercicio del poder político por parte de la multitudo desde el pensamiento de dos autores, Bartolo Sassoferrato y Marsilio de Padua. La revisión de los argumentos que ambos pensadores desarrollan 
permitirá indicar cómo, durante esta época, fue abordada la "teoría ascendente del poder" desde lo jurídico y lo político. El cruce de los argumentos que ambos proporcionan permite validar el ejercicio del poder político desde el colectivo, estableciendo con ello antecedentes para un camino distinto al emprendido por el liberalismo.

En el tercer apartado se presentará de qué modo la "teoría ascendente del poder" permite entregar elementos de análisis crítico para el despliegue de una democracia radical, desde el pensamiento político contemporáneo. De modo tal que la recuperación de esta teoría, además de hacer referencia al poder político ejercido por un colectivo, permite constatar que el campo de lo político se articula desde una heterogeneidad siempre en conflicto, que determina la constitución propia de este campo y que lo abre hacia otros modos de ejercicio y comprensión de las dinámicas de relación que en la actualidad se establecen.

\section{Antecedentes medievales para la comprensión de la "teoría ascendente del poder"}

Pierre Manent, en su libro Histoire intellectuelle du liberálisme, proporciona una sugerente esquematización conceptual del problema del poder en el mundo medieval, distinguiendo tres "formas políticas" que se establecen entre el paso de la Edad Media a la Modernidad, y que permiten comprender de qué modo el horizonte de la organización del poder en ellas se establece como un elemento que grafica, expresamente, las diferencias entre la "teoría ascendente del poder" $y$ la "teoría descendente del poder". Las figuras a las que hace referencia el autor en su texto son: imperio, ciudad e Iglesia.

El imperio, "C'est le rassemblement de tout le monde connu, de I'orbis terrarum sous un pouvoir unique" (Manent 18). Esta forma de organización política si bien había declinado en Occidente, durante fines del período medieval aún continuaba vigente en Oriente, y como modo de organización apuntaba a la búsqueda de un poder de orden universal. El emperador, el autokrator, era un monarca autónomo, de modo que todo lo que afectaba al imperio era preocupación del 
emperador. El imperio desde esta perspectiva se configuraba desde un horizonte de comprensión de carácter mundial, universal y único, por lo cual no podía existir ningún otro gobernante -distinto al emperador- que pudiera legítimamente pretender ser dominus mundi (Ullmann 2003). En este punto es relevante considerar como referencia, que una de las lecturas que validan la posición de Manent es la de Negri y Hardt en Imperio, cuando señalan que la genealogía del imperio es eurocéntrica y que este concepto propone un régimen que abarca la totalidad espacial del mundo civilizado (Hardt y Negri 2002; Kohan 2003).

En segundo lugar, se encontraba la ciudad como forma política : "C'est d'un espace public où les hommes, les citoyens deliberant, et décident de tout ce qui concerne leurs "affaires communes". C'est l'idée de la maîtrise par la association humaine de ses conditions d'existence" (Manent 19). La ciudad como forma de organización política se vitaliza a fines del mundo medieval, a partir de la recuperación de la obra de Aristóteles durante la Baja Edad Media, pues estos textos permiten restablecer el ideal de la ciudad como organización autónoma y autárquica, que responde -simultáneamente- tanto a un registro ético, como político (1253a). La ciudad desde esta perspectiva, no sólo representa una forma de ejercicio del poder, sino también un ideal antropológico, en que ser humano y ciudad son parte de un mismo bucle de sentido (Sartori 29 y ss.).

Alrededor de 1250 se tradujo del griego al latín la Ética Nicomaquea (1248, Grosseteste) y la Política (1260-1264, Moerbeke) de Aristóteles [...] Con la introducción del pensamiento, la discusión cambió de punto de partida: la antropología del pecado original fue sustituida por la antropología aristotélica del hombre por naturaleza racional y político [...] Partiendo del carácter natural de la sociabilidad del hombre se presentaron nuevos caminos para solucionar la cuestión del sentido y de la calidad de la vida en comunidad. (Vollet 26)

La tercera forma política que describe Manent es la Iglesia, la que estaba fuera del registro del pensamiento político clásico, pero que 
marcará el desarrollo político de Europa. Manent consigna que a partir del Medioevo, "le developpement politique de l'Europe n'est compréhensible que comme l'histoire des résponses aux problèmes posés par l'Église [...] chaque résponse institutionelle posant à sont tour des problémes inédites et appelant l'invention de résponses nouvelles" (Manent 19-20). Esta tercera "forma política" de representación y ejercicio del poder, permite evidenciar una estructura política completamente distinta a la que subyace a las dos anteriores, imperio y ciudad, en cuanto el poder deja de estar presente en la inmanencia de la interacción humana y comienza a ser representado desde una posición radicalmente extrínseca al mundo.

Esta nueva forma de comprensión del poder permite una articulación distinta para el campo de lo político, en cuanto, esta organización se basa en un poder que no surge de los individuos o del emperador, sino directamente de la divinidad, la cual ejerce poder y providencia sobre territorios e individuos desde una posición externa a estos (Rojas 2015).

El poder reside originalmente en un ser supremo, que con el predominio del Cristianismo se identificó con la misma divinidad. En el siglo V, san Agustín había dicho que Dios daba sus leyes a la humanidad por medio de los reyes. Y en el siglo XIII santo Tomás de Aquino expresó la misma idea al afirmar que el poder descendía de Dios. También puede imaginarse en este caso una metafórica pirámide, si bien con la totalidad del poder concentrada en su vértice. (Ullmann 1999 15)

El desglose de las "formas políticas", que realiza Manent, permite establecer de modo sucinto, que ciudad e imperio responden a formas de organización "naturales", no así la Iglesia, pues ésta quiebra el modo de relación entre las formas políticas y el ejercicio del poder, al establecerse un modelo descendente para éste, quedando el ser humano completamente ajeno a su origen y control. "Hay por consiguiente una sociedad política natural, pero sobre ella se levanta la sociedad cristiana, en la que el Papa como rey de reyes dispone de un poder supremo que abarca lo temporal y lo espiritual" (Truyol y Serra 393). Con la inclusión de esta tercera "forma política", el poder 
del emperador y el poder que se ejerce en la ciudad, quedan subsumidos y cercenados, pues la posibilidad de su ejercicio comenzará a vincularse a la gracia divina.

El lugar en el que se hará patente el desplazamiento del poder, por medio de la inclusión de lo eclesial en el mundo terreno, es en la civitas en tanto iuris societas. Giuseppe Sergi, en su obra La idea de la Edad Media, señala expresamente que el término civitas designa un centro urbano habitado por un obispo (108), dando cuenta a partir de ello que en la civitas confluye tanto una organización de orden humano como eclesiástico de modo simultáneo. La ciudad como forma política desaparece en pro del surgimiento de una sociedad civil que se constituirá como un lugar de conflicto permanente entre la potencia inmanente de lo social y el poder trascendente vinculado a la "teoría descendente del poder", cuyo despliegue generará una coacción sistemática sobre lo social. En efecto, "La Iglesia expresa la "totalidad" del mundo. Pero su universalismo toma cada vez menos la forma de imperium para pasar a revertir la de una respublica Christianum, sometida a la auctoritas del Pontífice" (Touchard 162). Por esta razón el Estado, durante el inicio de la Modernidad, comenzará a organizarse del mismo modo que el poder Eclesiástico en el Medioevo, pues con ello emula una forma de ejercicio de poder que garantiza la posesión hegemónica del mismo frente al colectivo.

Este breve itinerario hasta el momento trazado permite identificar que el discurso legitimador de la autonomía de las ciudades, que comienza a fraguarse en la Baja Edad Media, se contrapone directamente a la "teoría descendente del poder" de sesgo monárquico e hierocrático², que acabará por imponerse.

\footnotetext{
2 "A esto debe sumarse la mención de Dionisio Areopagita y su doctrina hierocrática, aquella según la cual hay un orden jerárquico cuyo principio es que lo inferior debe someterse a lo superior. De la jerarquía se desprende que si todo poder viene de Dios, desciende en primera instancia a lo superior. Sin duda lo espiritual es superior a lo temporal. De allí se deriva la siguiente conclusión: el emperador o el rey reciben su poder del Papa" (D’Amico 185).
} 
En efecto, en la historia de Occidente la gran triunfadora entre estas dos teorías es la "teoría descendente del poder", la cual adquiere grados insospechados de legitimidad a partir de la Modernidad, pues ella no es otra cosa que una derivación y concreción de orden práctico del método deductivo de raciocinio, que desde el mundo antiguo ha mantenido predominio en el desarrollo del pensamiento de Occidente (Ullmann 1999 19), y que ha pretendido resolver el problema de lo político desde la institución de una entelequia que dictamine el decurso del mundo. Sin embargo, a partir de lo expresado en este apartado, aquello que se quiere destacar es el surgimiento de la ciudad como aquella "forma política" que permite dar cuenta de la inmanencia del poder desde una teoría ascendente del mismo, en cuanto desde ésta es posible situar el ejercicio del poder desde una subjetivación colectiva: "Conforme crecían en población, las ciudades medievales... [tuvieron] que dotarse de normas propias para regular la vida social y decidir la configuración en un proceso constituyente" (Bayona Aznar 151-152). Walter Ullmann en su texto Historia del pensamiento político en la Edad Media considera, al referirse a la "teoría ascendente del poder", que "esta teoría ascendente del gobierno puede denominarse también teoría popular del gobierno, porque el poder residía, en su origen, en el pueblo" (14).

Desde esta perspectiva, siguiendo a Ullmann, la "teoría ascendente del poder" se vincula directamente con la pregunta por el origen de lo político, desde un doble registro, pues por una parte cuestiona la legitimación jurídica del poder descendente construido desde el Medioevo a los inicios de la Modernidad o Renacimiento, y que se mantiene hasta la actualidad, $y$, por otra parte, cuestiona la matriz teológico-política que se ha impuesto como referente último para este campo (Cf. Esposito 2013), a través del posicionamiento del poder político en la inmanencia de la multitud, entendida esta última como un cuerpo político colectivo en ejercicio (Cf. Butler 59).

el poder residía originalmente en el pueblo, era éste quien en sus asambleas populares elegía a un jefe para las guerras, un duque, un rey, etc. Dicho jefe no tenía más poderes que los que la asamblea electoral le había concedido. Se 
le consideraba como representante de la comunidad, y por lo tanto era responsable ante la asamblea popular. En consecuencia, existía un derecho a resistirse a las órdenes del gobernante en tanto que dirigente. Este derecho de resistencia explica la facilidad con que era depuesto y apartado un rey si, en la opinión del pueblo, había dejado de representar su voluntad. (Ullmann, 1999 14).

Sin embargo, esta teoría durante el siglo XIII, después de una serie de invasiones a las ciudades italianas, que luchaban por mantener su autonomía territorial e independencia política del papado, son controladas, anexadas y ocupadas por éste: "El resultado fue que, al término del siglo XIII, el Papado había obtenido el dominio directo temporal de una gran zona del centro de Italia, así como una medida considerable de influencia sobre la mayor parte de las grandes ciudades del Regnum Italicum" (Skinner 34). Una vez que se logró, con el concurso de los habitantes de las ciudades libres italianas, desmantelar los ataques del imperio español y de los reyes franceses, el Papado arremetió, con las mismas intenciones que estos, en contra de ellas, no sólo con ejércitos, sino que, también, con una batería conceptual construida desde la hegemonía que ejercía sobre el pensamiento jurídico y legitimadas a partir del ejercicio fáctico del poder. Se establece así una íntima relación entre la jurisprudencia y la praxis de la política, y el acto de gobernar se mediatiza a través de la promulgación y la aplicación de leyes; "Las idea políticas de la Edad Media pueden deducirse del contenido de las disposiciones de justicia, y el concepto de justicia impregnaba y daba sentido a la ideología política medieval. La idea de justicia se materializaba en la ley" (Ullmann, 1999 16).

Lo jurídico se presenta, entonces, como la legitimación del origen y la fuente del poder del soberano, cuestión que adquiere una centralidad que terminará articulando un campo de discusión y acción que estaba latente, pero poco definido, hasta la Baja Edad Media y que tendrá un fuerte influjo en la elaboración de la "teoría ascendente del poder", en cuanto a partir de esta teoría se planteará la correspondencia directa entre el derecho y los hechos y junto a ello se cuestionará el lugar donde reside el poder. Por su parte, Claudia D'Amico en el texto "El 
conciliarismo y la teoría ascendente del poder en las postrimerías de la Edad Media", da cuenta de cómo el conciliarismo de la iglesia responde a un movimiento jurídico en el que el tema del populus encontró su hábitat jurídico (8). Estas dos referencias permiten considerar que el problema de la "teoría ascendente del poder", debe ser abordado tanto desde una esfera política como jurídica, para comprender el impacto que la recuperación de este modo de ejercicio del poder proporciona al desarrollo del pensamiento político contemporáneo.

A partir de lo señalado, la ciudad como "forma política" durante la Baja Edad Media se constituye como la expresión de un "autogobierno [que] se basa en la eficiencia del control administrativo de la vida social e implica el ordenamiento republicano, en tanto que la fuente del poder reside en el conjunto de ciudadanos" (Bayona Aznar 154-155). La ciudad, por consiguiente, permitirá a través del ejercicio de poder colectivo que ejercen sus habitantes, extender el término Popolo al conjunto de ciudadanos que habitan en la ciudad, al punto que este hecho es considerado como el acontecimiento político más relevante que ocurre entre el año 1200 al 1300 (Bayona Aznar 163), en tanto que posibilitará el surgimiento de una "teoría ascendente del poder", que arrogaba al pueblo incluso el derecho a resisitirse a las órdenes del gobernante. "Este derecho de resistencia explica la facilidad con que era depuesto y apartado un rey si, en la opinión del pueblo, había dejado de representar su voluntad" (Ullmann 1999 14).

\section{Emergencia de la "teoría ascendente del poder"}

La apuesta teórica de este texto radica en la recuperación de los elementos que determinan el surgimiento de la "teoría ascendente del poder", que si bien es parte del mundo medieval, su presencia y desarrollo ha quedado desplazada y silenciada en la historia oficial que se trasmite acerca de las teorías políticas del mundo medieval. En esta discusión es relevante destacar el aporte realizado por algunos de los pensadores de esta época que, paulatinamente, contribuyeron a elaborar esta teoría. En el presente apartado se revisará el influjo de dos de ellos, ambos coetáneos, pero que abordan el problema 
desde diversas aristas, permitiendo con ello comprender el nutrido entramado jurídico-político que subyace tras ésta.

Uno de los primeros teóricos medievales en contribuir a la configuración de una "teoría ascendente del poder" fue el jurista Bartolo Sassoferrato (1314-1357), mayor civilista del mundo medieval (Bayona, 2009), quien comienza a desarrollar una estrategia de interpretación de los textos jurídicos del derecho romano para defender la independencia del poder temporal de los príncipes y magistrados de las pretensiones hegemónicas del papado.

Bartolo fue originario del Regnum Italicum, estudiante en Bolonia y después profesor de Derecho Romano en diversas universidades de la Toscana así como de la Lombardía [...]. Claramente manifestó la intención de re-interpretar el código civil romano de tal manera que diera a las comunas lombarda y toscana una defensa jurídica y no sólo retórica de su libertad contra el Imperio. El resultado no sólo fue iniciar una revolución en el estudio del derecho romano [...], sino también dar un gran paso hacia el establecimiento del concepto, distintivamente moderno, de una pluralidad de autoridades políticas soberanas, cada una de ellas separada de las otras, así como independiente del Imperio. (Skinner 29)

La estrategia de Sassoferrato consistía en impugnar la prevalencia de la ley por sobre los hechos, al punto de considerar que "cuando la ley y los hechos chocan, es la ley la que debe entrar en conformidad con los hechos" (Skinner 29), contraviniendo con ello la suposición cardinal de los glosadores, que tenía como condición que cuando la ley no está en armonía con los hechos, son los hechos los que deben acomodarse a la ley. Dicho en otras palabras, para Sassoferrato la ley debe ceder ante la evidencia de los hechos, adaptarse a la contingencia del mundo y cuestionar, por consiguiente, la universalidad de una ley natural.

El argumento del jurista se sustentaba en la idea de que las ciudades poseen el legítimo derecho a ser libres para administrar sus asuntos 
políticos, rompiendo a partir de este principio con la idea de que el derecho positivo se basa en el derecho divino, y que el poder del emperador es de orden universal.

En su glosa al Digesto, así como en su Tractatus de represaliis, distingue Bartolo el señorío universal de iure del Emperador y su señorío limitado de facto. De derecho, el emperador es señor de todo el orbe, aunque de hecho no sea en todas partes obedecido. Junto al Imperio efectivo están, dentro de la misma cristiandad, las ciudades y reinos que no reconocen superior (superiorem non recognoscentes) [...] El "reino que no reconoce superior" es la prefiguración del Estado moderno, y Bartolo, que a pesar de su adhesión a la idea imperial se ve constreñido a seguir prácticamente a los legistas franceses, fue un primer teórico de la soberanía en sentido moderno. (Truyol y Serra 404-405).

De esta manera, uno de los rasgos elementales de la soberanía, a saber, el derecho de delegar jurisdicción a jueces menores, queda objetado en caso de que la ciudad, vale decir los ciudadanos, o más bien, como lo señalara Marsilio de Padua, sus representantes, los valentiors pars, reconocen libremente a un superior. Sin embargo hay una situación en la que sí es legítimo que la ciudad ejerza su soberanía, y será este el punto de partida teórico y jurídico de las reivindicaciones de autonomía republicana de las ciudades.

Claramente hay una revolucionaria pretensión política implícita en esta defensa de las ciudades italianas y su Imperium: la afirmación de que se las debe reconocer como cuerpos soberanos totalmente independientes. Esta conclusión finalmente es expuesta por Bartolo en forma de un epigrama del que puede decirse que encarna la esencia misma de sus ataques a los glosadores y demás defensores del Imperio. Declara que, siendo las ciudades gobernadas por "Pueblos Libres" que ejercen su propio Imperium, entonces puede decirse, en realidad, que constituyen sibi prínceps, un prínceps en sí mismas. (Skinner 31) 
Tanto Bartolo Sassoferrato, como Marsilio de Padua, apuestan por una racionalidad que permita la construcción de un orden justo, que respete la libertad de los individuos de manera positiva y que promueva la autonomía de las comunidades, en términos jurídicos y políticos, de modo de establecer que el poder tiene una base terrena: "En los comentario jurídicos Bartolo se ocupó de temas constitucionales [...] Situó la clave del autogobierno de las ciudades en el derecho consuetudinario, basándose en que el elemento esencial es el consentimiento del pueblo" (Bayona Aznar 375), de modo que el poder que ejerce un ser humano sobre los otros hombres, deriva directamente de estos. La reflexión que establece y propone Bartolo permite que sigan existiendo en su época ciudades libres que son capaces de elaborar, implementar y modificar su propia ley. Entre las ciudades que conservaron su independencia durante este período y que dan testimonio de la resistencia de las ciudades libres italianas ante la implementación del Estado, como representación moderna de la "teoría ascendente del poder", son dos: "la[s] de mayor importancia para la historia de la humanidad: Florencia, ciudad de actividad incesante [...] y Venecia, una ciudad de aparente estancamiento y política discreta" (Burckhardt 88-89).

Marsilio de Padua (1275/80-1342), por su parte, se erige como uno de los filósofos más destacados en lo que respecta a la instauración y defensa de la secularización del poder político que comienza a elaborarse a fines de la Edad Media. Este filósofo contó con una valorada reputación en su época que lo condujo a ser rector de la Universidad de París, pero una vez publicado el libro Defensor pacis (1324), obra en la que aborda estos problemas, desaparece de la escena pública, debido a que este texto fue condenado y su autor perseguido.

La obra Defensor pacis es reconocida como la aplicación política del averroísmo latino y del naturalismo aristotélico (Cf. Sabine 233 y ss). En este texto el autor se refiere de forma directa al problema del poder, señalando que éste procede del pueblo: "El poder de dictar leyes corresponde al pueblo o a la valentior pars del pueblo. Este poder puede delegarse a una o varias personas, pero sin que el pueblo o su valentiors pars pierda su calidad de legislador ordinario" (Tuyol y Sierra 412). 
Este énfasis que el autor entrega al lugar del pueblo como subjetividad política colectiva radica en el hecho que, para "Marsilio, el principio ordenador de toda comunidad civil es la voluntad común de todos los ciudadanos, aunada para el bien superior de la civitas, por encima de las voluntades particulares" (Barcalá 324), dando un giro a través de su pensamiento a todo el horizonte teórico desplegado en su época, y que con el tiempo dio pie a la configuración del liberalismo político.

La diferencia entre el liberalismo político y aquello que se quiere destacar, remite al modo de ejercicio del poder político, que en el caso del liberalismo se caracteriza por la concentración del poder en el individuo cuyo vínculo con el otro es por medio de la cooperación, pero que sin embargo tiene su origen en la constitución individual de la persona como un ser humano libre e igual (Rawls 2013). Esta forma de ejercicio de poder se fue imponiendo y desarrollando con fuerza a partir de la modernidad, al punto de establecerse como uno de los modos privilegiados para el desarrollo de la filosofía política, y de acuerdo al análisis de un variopinto grupo de filósofos críticos de nuestra época, estas consideraciones son las responsables de la erosión del campo de lo político: "la crisis política es la crisis de la modernidad; o, si invertimos la proposición, la crisis de la modernidad consiste, esencialmente, en la crisis de la filosofía política moderna" (Abensur 6).

De este modo los enunciados que conducen a Marsilio, a considerar que, si bien existe un grupo o una parte gobernante, que dentro de su pensamiento puede ser considerada como el verdadero corazón del cuerpo social, aun cuando tenga una función directiva hacia los otros miembros, el poder que detenta se basa en una dependencia directa ante todos los ciudadanos a quienes representa, y es en esta representación del poder del colectivo en la que radica la autoridad pública expresada por la ley humana (Barcalá 2012).

Para el filósofo paduano el poder es único, y radica en la multitudo como subjetivación colectiva, en cuanto ésta surge de la inmanencia constitutiva de los individuos y no desde una trascendentalización, por lo cual, con ello no sólo respalda el poder de los gobernantes en tanto valentiors pars, sino simultáneamente cuestiona toda cons- 
trucción de poder político que provenga de un horizonte distinto al de la ciudad como organización política autárquica y autónoma, cuestionando a partir de ello, la posibilidad de que el poder radique y descienda desde una unidad, ya sea divina o humana, para ser ejercida sobre el pueblo.

Esta interpretación acerca del modo como surge el poder, también le permite al paduano realizar una distinción entre los modelos de gobierno, distinta a la aristotélica que los clasifica de acuerdo a la orientación al bien común, ante lo cual la monarquía, la aristocracia y la democracia son partes de los gobiernos que el Estagirita considera positivos, pues a pesar de que tienen distinta cantidad posee igual cualidad (1279a). En el caso de Marsilio las distinciones entre los modelos de gobierno se considerarán correctas o incorrectas de acuerdo a la posibilidad de participación que tienen los ciudadanos en el gobierno o en el consejo, rompiendo con ello toda posibilidad de que el poder sea algo que descienda de cualquier tipo de entelequia o que pueda ser desvinculado del poder del colectivo.

Estas breves referencias a dos autores, Bartolo Sassoferrato y Marsilio de Padua, como representantes emblemáticos de la "teoría ascendente del poder" en la Baja Edad Media, permite indicar que en este período de la historia de Occidente no sólo emerge esta teoría, sino que se desarrollan un buen número de sólidos argumentos jurídicos y políticos, cuyo propósito principal radicaba en permitir la independencia y autonomía de las ciudades y sus habitantes, otorgando con ello una perspectiva distinta a la ofrecida a través de la "teoría descendente del poder", que enfatiza el poder del soberano.

Romper, quebrar este férreo cerco teórico y simbólico era fundamental para lograr dar un sustento político sólido y duradero a las demandas de autonomía de las ciudades por sobre las pretensiones de hegemonía despótica de los emperadores. Esto sienta las bases de un discurso filosófico y político que se infiltrará de manera subrepticia, subterránea y soterrada, emergiendo en momentos de crisis y de fuertes luchas teológico-políticas, hasta los inicios de la modernidad. (Skinner 319) 
La disputa por el origen y la fuente del poder -ascendente o descendente- adquiere importancia en el mundo medieval, pero con el paso del tiempo se irá dando forma a la supremacía del poder de los príncipes por sobre la autonomía de las comunidades. La concentración del poder político y religioso, que emana su influjo hacia abajo, demandando obediencia y devoción a los súbditos, se irá consolidando y sólo se mantendrá la organización del poder desde la base popular en pequeños "enclaves populistas dentro del reino teocrático" (Ullmann 1999 153). En efecto, la idea de la existencia de una dependencia del soberano a una ley de orden inmanente que emana desde el cuerpo del pueblo será una hipótesis transgresora que permite aún hoy movilizar un discurso emancipador.

Esta confrontación de posiciones entre la "teoría descendente del poder" con los modos de organización de la "teoría ascendente del poder" sigue siendo de enorme relevancia para el pensamiento político, debido a que esta última rompe con las ataduras teológico-políticas del discurso dominante y tiene como una de sus fuentes la inmanencia de la potencia política, en tanto potencia democrática de la multitudo, que en la Baja Edad Media queda validada a partir del doble registro que ofrece la "teoría ascendente del poder", por una parte, el plano de lo jurídico, en cuanto es el pueblo el que constituye y determina la ley (Bartolo Sassoferrato), permitiendo con el ello el autogobierno de las ciudades $y$, por otra parte, desde el plano de lo político, en tanto es en el pueblo donde se constituye y reside el poder político de la ciudad (Marsilio de Padua).

\section{De la multitudo a la democracia radical}

La constitución jurídica y política rastreada en la Baja Edad Media para la comprensión del poder de la multitudo como cuerpo político colectivo, no es otra cosa que la pre-configuración del pueblo como subjetividad política. Para Negri esta configuración, siguiendo el pensamiento de Spinoza puede ser abordada desde dos aristas, la primera se define de modo tal que "las singularidades constituyen la multitud según principios de utilidad" (85), por lo cual no habría tras de ésta 
un proyecto común. En cambio, el segundo modo para la multitud como subjetivación colectiva en el pensamiento del filósofo político contemporáneo se caracteriza por la condición de la sociabilidad humana, es decir, "en la relación entre singularidades y la multitud en tanto proceso constitutivo" (85).

En palabras de Baruch Spinoza, nada hay de más provechoso para el hombre que el mismo hombre, pues sólo así se potencia el conatus que surge de la expresión del cuerpo social (Spinoza, E IV P18, esc. c), y que a partir de la "teoría ascendente del poder" puede constituirse y organizarse para dar voz a la vitalidad propia del campo de lo político.

El poder político es el derecho natural de la multitudo que, en adelante, llamaremos pueblo. Eso significa que la soberanía no es sino el derecho natural colectivo que existe sólo mientras exista sujeto político instituyente, pues [...] el poder instituyente (o sujeto instituyente) no tiene existencia virtual. (Chaui 196)

Por consiguiente, el cuestionamiento que permite retomar la senda de la "teoría ascendente del poder" en el mundo político contemporáneo, consiste en preguntarse por las condiciones de posibilidad para la construcción de un cuerpo político colectivo o multitudo, en el que radique el ejercicio del poder. Didi-Huberman, en el texto "Volver sensible/hacer sensible", resume en breves palabras la posición arendtiana acerca de este punto, y que sirve como marco para comprender la importancia de recuperar la "teoría ascendente del poder" para el pensamiento político contemporáneo.

Hannah Arendt decía que nunca llegaremos a pensar la dimensión política mientras nos obstinemos a pensar en el hombre, porque la política se interesa justamente por algo distinto, que son los hombres, cuya multiplicidad se modula siempre de distinta manera, ya sea conflicto o comunidad (61).

En efecto, recuperar la "teoría ascendente del poder", como fue presentada en la Baja Edad Media por Bartolo Sassoferrato y Marsilio de Padua, permite aproximarse al campo de lo político no desde el 
individuo sino desde el colectivo, posibilitando la reflexión política que extraña Arendt y que considera que ha impedido aproximarse de forma indicada a la escena política.

El pueblo como subjetivación colectiva o multitudo se constituye, por consiguiente, como aquel cuerpo político compuesto por una heterogeneidad, cuyas demandas se expresan de forma colectiva sobre el territorio en el que se ejerce su poder (Chaui 2004). La multitudo al constituirse como el modo a partir del cual la subjetivación política se expresa en el campo de lo político, su forma y construcción apunta siempre a una autopoiesis -que surge de un proceso político siempre particular-y que no culmina en la homogeneización de una demanda, sino en la organización de este colectivo desde su diferencia, de lo contrario la construcción que emana de esta subjetivación puede ser confundida con un tipo de nacionalismo popular homogeneizante o con una modalidad de imperialismo contemporáneo (Khiari 94), que neutralizan y clausuran toda diferencia.

Entre las discusiones teóricas que posibilita la recuperación de la "teoría ascendente del poder" para el mundo contemporáneo, aparece como posibilidad repensar desde otros referentes a la democracia (Negri 19), para dar paso a una democracia entendida desde la posición de la multitudo como subjetividad colectiva, y a partir de la cual el poder se conduzca desde el derecho natural al derecho civil, transformando las lógicas de fuerzas contrapuestas del campo de lo político en lógicas de poder, a través de una sui juris (Chaui 2004), en la cual el colectivo se instituye como el encargado de mantener y ejercer el poder dentro del territorio.

Jean Jacques Rousseau, en relación con aquello que hasta el momento se ha presentado acerca de la "teoría ascendente del poder", en referencia a la reinterpretación de la democracia, considera que así como se plantea es un modelo de gobierno perfecto para la comunidad política, sin embargo, el más complejo de preservar.

Agreguemos que no hay gobierno más sometido a las guerras civiles y a las agitaciones intestinas que el democrático popular, porque ninguno tiene una tendencia tan fuerte 
y constante a cambiar de forma, ni exige más vigilancia y coraje para ser mantenido en ella [...] un gobierno tan perfecto no conviene a los hombres. (Rousseau 119-120)

La referencia que realiza Rousseau permite dimensionar la complejidad que conlleva instituir un organización política que se valida desde el ejercicio del poder por parte de la multitudo. Sin embargo, es precisamente esta condición conflictiva de la escena política otro de los puntos relevantes que permite recuperar la "teoría ascendente del poder", en cuanto ésta cuestiona la concentración del poder en un sujeto particular o colectivo exclusivo, que diluya el conflicto del campo de lo político. De este modo es posible sostener que toda trascendentalización del poder puede ser leída como un intento de neutralizar el campo de lo político. El poder, cuando es comprendido como una pugna de fuerzas entre quienes componen la multitud, establece a partir de ello el estatuto de lo político desde un campo de fuerzas (Lefort 2010) siempre en tensión. En cambio, cuando se otorga una constitución trascendente al poder, éste se sustrae de la inmanencia, neutralizando con ello el campo de lo político, al desvincular al poder del mismo.

En cambio, la "teoría ascendente del poder" aquello que viene a recuperar es el posicionamiento del poder, precisamente, en la constitución de una multitudo como expresión de cuerpo político que se constituye desde la diferencia, y que no busca la unidad como finalidad de su propia constitución, sino el constante movimiento del flujo de fuerzas en tensión. La democracia desde esta perspectiva adquiere una condición distinta a aquella con la que se la ha investido desde la antigüedad, pues de acuerdo a lo que se expresa a partir de la recuperación de la "teoría ascendente del poder", sólo se constituye el campo de lo político cuando en éste se expresan fuerzas en tensión y disputa, que mantienen vivo el conflicto ${ }^{3}$.

3 El paradigma conflictivista a la base de este artículo, dada la extensión del mismo no puede ser abordado expresamente, sin embargo, se indica que este análisis se desarrolló a partir de la reflexión que el texto de Chiesa y Toscano realizan acerca de la Italian Theory, donde establecen que la diferencia del pensamiento italiano contemporáneo radica en repensar la relación entre filosofía y política, partir de la 
En otras palabras, las condiciones de un Estado democrático dependen finalmente de un ejercicio de la soberanía popular que ningún orden democrático logra contener del todo. Podría ser pensada como un poder extraparlamentario sin el cual ningún Parlamento puede funcionar, al mismo tiempo que representa una amenaza de difusión o incluso disolusión de todo Parlamento. Podríamos llamarla una energía "anarquista" o un principio de revolución permanente en el interior del orden democrático. (Bensaïd 43)

Esta modificación en la comprensión de la constitución y ejercicio del poder a partir del colectivo, permite dar cuenta del conflicto como fuerzas en contradicción en el campo de lo político, lo que a su vez permite que las mismas sean leídas como la potencia de una democracia radical, y no como una voz que debe ser acallada. Además, a partir de la cita de Bensaïd, es posible considerar que la "teoría ascendente del poder" evidencia que el campo de lo político para constituirse debe considerar como principio el conflicto y al pueblo como multitudo

Por ende, los movimientos sociales y/u organizaciones ciudadanas que cuestionan los límites para la intervención y participación política, aquello que constatan a través de su ejercicio la expresión de un conflicto, que impacta tanto en el modo de organización política, así como también, en los procesos de subjetivación que estos implican, "en mi opinión todo el repertorio de categorías políticas modernas, basado en la polaridad entre derechos individuales y soberanía estatal, contribuye a hacerlos cada vez más irresolubles" (Esposito 2009 125), por lo cual siguiendo a Esposito, es necesario revisarlos al punto de volver a preguntar: "¿Qué es la política? ¿De qué raíz emana?" (Zambrano 201).

En este registro son muchos los filósofos que durante la segunda mitad del siglo XX y lo que va del XXI se han consagrado a pensar, plantear o deconstruir el problema de la democracia, y que durante los últi-

revisión de autores y categorías anteriores a la modernidad, de modo de ingresar a partir de otros referentes a dar cuenta de las dinámicas de relación contemporánea (Cfr Serratore, 1-14). 
mos años ha dado fuertes evidencias de su validez como propuesta teórica y política para la construcción de una democracia radical que contribuya al decurso de los procesos de subjetivación colectivo implicados en ella, apostando a la constitución de una subjetivación desde la diferencia, que permita romper con el intento de cooptar o neutralizar el campo de lo político.

\section{Conclusión}

Recuperar los elementos que configuran la "teoría ascendente del poder", desde su origen medieval, permite resituar el conflicto como elemento constituyente del campo de lo político, en cuanto a partir de esta teoría es posible romper con toda trascendentalización y teleología para este campo, lo que redunda en desplazar al "orden" como fundamento y finalidad de la política.

La apuesta teórica que subyace tras esta recuperación -para la discusión política- radica en considerar a la política como "reforma, creación, revolución siempre, por tanto: Lucha -conjunción- entre el individuo y la vida" (Zambrano 204), por lo cual es el cuerpo colectivo aquello que permite que esta constitución de lo político no se pierda o diluya en la naturalización de la ley o del poder desde una condición descendente del mismo.

Desde esta perspectiva, el carácter del colectivo debe ser siempre considerado desde su diferencia, pues precisamente es en esta condición en la que basa su fuerza y vitalidad. En efecto, el carácter de la multitudo que se ha presentado se alza como parte del proceso constitutivo del campo de lo político, en tanto que esta subjetivación colectiva, aquello que expresa es que los actores que componen este colectivo se enfrentan respecto de intereses, la mayor de las veces contrapuestos, lo que implica dar fin a la pretensión de una comunidad que se organiza a partir de una unidad mítica perdida (Bensaïd 41), o a partir de una demanda impredecible y multiforme de una colectividad espontánea y homogénea.

Además, aquello que se propone a partir de la recuperación de los elementos que determinan una "teoría ascendente del poder" es 
que el conflicto en el campo de lo político no se reduzca al inicio de la construcción de este campo, sino más bien se considere como su propio ejercicio y despliegue (Esposito 1984). Estos enunciados permiten confrontar otras posiciones de filósofos políticos contemporáneos, que persisten en pensar el campo de lo político desde el carácter individual de la subjetividad, ya sea aludiendo a un modelo de gobierno autoritario (Schmitt 2012) o a un modelo de gobierno democrático con énfasis en el pluralismo (Mouffe 2012).

Esta apuesta teórica que se ha presentado busca desplazar el campo de lo político desde una lógica del consenso hacia una lógica del disenso, lo que no es otra cosa que reconocer que cada uno de los conflictos que se presentan corresponden a realidades y situaciones históricamente determinadas y diferenciadas, que no pueden ser homogeneizadas debido a que éstas responden siempre a un orden particular (Ranciere 2007), condición que además expresa la determinación práctica de esta disciplina, en cuanto en el campo de lo político se da cuenta de procesos dinámicos y complejos que no pueden ser delimitados de modo absoluto, ni fundarse en principios trascendentes (Nancy 2010).

Desde esta perspectiva se ha intentado por medio de la recuperación de algunos de los elementos centrales que configuran la "teoría ascendente del poder", concebir una democracia radical desde la multitudo, que considera al conflicto como lo propio del campo de lo político. En efecto, aquello que el término multitudo evidencia son las fluctuaciones del campo de lo político, siendo éstas consideradas la potencia misma de la democracia, poniendo en entredicho cualquier tipo de fundamento trascendente para la misma.

Esta radicalidad que presenta este modelo de democracia que se vincula con la "teoría ascendente del poder" tiene como ventaja que la subjetividad colectiva no es subsumida bajo un cuerpo colectivo unitario y homogéneo, sino que esta subjetividad colectiva responde a una multitudo en que la diferencia es parte constitutiva de la misma, y que, precisamente, es esta diferencia la que vitaliza y moviliza el constante conflicto que determina el campo de lo 
político. Por lo tanto, la multitudo no sólo garantiza la constitución de una democracia radical, sino que a través de ésta se constituye el propio campo de lo político.

\section{Bibliografía}

Abensour, Miguel. Para una filosofía política crítica. Ensayos.: Anthropos, Barcelona, 2007.

Aristóteles. La política. Gredos. Madrid. España, 1982.

Barcalá Muñoz, Andrés. "Edad Media". Ed. Fernando Vallespín. Historia de la teoría política, 1. Alianza. Madrid. España, 2012.

Bayona Aznar, Bernardo. El origen del Estado laico desde la Edad Medio. Tecnos. Madrid. España, 2009.

Bensaïd, Daniel. "El escándalo permanente". Giorgio Agamben et al, Democracia ¿en qué Estado? Prometeo. Buenos Aires. Argentina, 2010.

Burckhardt, Jacob. La cultura del renacimiento en Italia. Akal. Madrid. España, 2012.

Butler, J."“'Nosotros el pueblo". Apuntes sobre la libertad de reunión". Alan Badiou et al. ¿Qué es un pueblo? LOM. Santiago de Chile, 2014.

Chaui, Marilena. Política en Spinoza. Gorla. Buenos Aires. Argentina, 2004.

D'Amico, Claudia. "El conciliarismo y la teoría ascendente del poder en las postrimerías de la Edad Media". Comp. Atilio Borón. La filosofía política clásica. De la Antigüedad al Renacimiento. CLACSO - EUDEBA. Buenos Aires. Argentina, 2000.

Didi-Huberman, George. "Volver sensible /hacer sensible". Alan Badiou et al. ¿Qué es un pueblo? LOM. Santiago de Chile, 2014.

Esposito, Roberto. Ordine e conflitto. Machiavelli e la letteratura política del Rinascimento italiano. Liguori. Napoli. Italia, 1984.

paña, 2009.

Comunidad, inmunidad y biopolítica. Herder. Barcelona. Es-

Due. La macchina della teología política e il posto del pensiero.

Einaudi. Torino. Italia, 2013.

Hardt, Michel y Antonio Negri. Imperio. Paidós. Buenos Aires. Argentina, 2002. 
Khiari, Sadri. "El pueblo y el tercer pueblo". Alan Badiou et al. ¿Qué es un pueblo? LOM. Santiago de Chile, 2014.

Kohna, Néstor. "El imperio de Hardt \& Negri: más allá de modas, 'ondas' y furores".Comp. Atilio Borón. Filosofía política contemporánea: Controversias sobre civilización, imperio y ciudadanía. CLACSO Buenos Aires. Argentina, 2003. Web. 14 nov 2015.

<http://www.ultimorecurso.org.ar/drupi/files/kohan.pdf>

Lefort, Claude. Maquiavelo. Lecturas de lo político. Trotta. Madrid, 2010.

Manent, Pierre. Histoire intellectuelle du libéralisme. Pluriel. Paris. Francia, 2010.

Mouffe, Chantal. La paradoja democrática. El peligro del consenso en la política contemporánea. Gedisa. Barcelona. España, 2012.

Nancy, Jean-Luc. "Democracia finita e infinita". Giorgio Agamben et al. Democracia ¿en qué Estado? Prometeo. Buenos Aires. Argentina, 2010.

Negri, Antonio. Spinoza y nosotros. Nueva Visión. Buenos Aires. Argentina, 2011.

Ranciere, Jacques. El desacuerdo. Política y filosofía. Nueva Visión. Buenos Aires. Argentina, 2007.

Rousseau, Jean Jacques. El contrato social. Discursos. Losada. Buenos Aires. Argentina, 2005.

Rawls, John. El liberalismo político. Fondo de Cultura Económica. México, 2013.

Rojas Castro, Braulio. "Una interpretación de la filosofía política de Baruch de Espinoza desde el horizonte de la teoría ascendente del poder". Tesis. Pontificia Universidad Católica de Valparaíso, 2015.

Sabine, George. Historia de la teoría política. Fondo de Cultura Económica. México, 2009.

Sartori, Giovanni. Elementos de la teoría política. Alianza. Madrid. España, 2014.

Schmitt, Carl. Dialogo sul poter. Adelphi. Milano. Italia, 2012.

Serratore, Constanza. "Por qué una genealogía del pensamiento político italiano contemporáneo". Revista Pleyade, jul-dic 2013. Web. 6 nov. 2015. <http://www.caip.cl/wp-content/uploads/00.-Serratore.pdf>

Skinner, Quentin. Los fundamentos del pensamiento político moderno: I. Renacimiento. Fondo de Cultura Económica. México.

Spinoza, Baruch. Ética demostrada según el orden geométrico. Trotta. Madrid. España, 2009. 
Touchard, Jean. Historia de las ideas políticas. Tecnos. Madrid. España, 2010. Truyol y Serra, Antonio. Historia de la Filosofía del Derecho y del Estado. 1. De los orígenes a la Baja Edad Media. Trad. J. Pradera. Alianza. Madrid. España, 1989.

Ullmann, Walter. Historia del pensamiento político en la Edad Media. Ariel. Barcelona. España, 1999.

Escritos sobre teoría política medieval. Eudeba. Buenos Aires. Argentina, 2003.

Vollet, Matthias. "Vestigios protodemocráticos en la edad media tardía: Marsilio de Padua, Nicolás de Cusa". 1997 Ed. Rodolfo Arango. Filosofía de la democracia. Fundamentos conceptuales. Siglo del hombre. Bogotá. Colombia Zambrano, María. Horizontes del liberalismo. Morata. Madrid. España, 1996. 